\title{
Separation and HPLC Characterization of Active Natural Steroids in a Standardized Extract from the Serratula coronata Herb with Antiseborrheic Dermatitis Activity
}

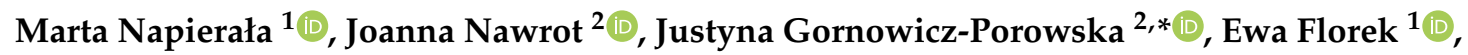 \\ Arletta Moroch ${ }^{2}$, Zygmunt Adamski ${ }^{3}$, Anna Kroma ${ }^{2}$, Izabela Miechowicz ${ }^{4}$ (i) and \\ Gerard Nowak ${ }^{2}$ \\ 1 Laboratory of Environmental Research, Department of Toxicology, Poznan University of Medical Sciences, \\ 30 Dojazd Street, 60-631 Poznan, Poland; martan@ump.edu.pl (M.N.); eflorek@ump.edu.pl (E.F.) \\ 2 Department of Medicinal and Cosmetic Natural Products, Poznan University of Medical Sciences, \\ 33 Mazowiecka Street, 60-623 Poznan, Poland; joannac@ump.edu.pl (J.N.); arletam20@wp.pl (A.M.); \\ kromkaania@interia.pl (A.K.); gnowak.gerard@gmail.com (G.N.) \\ 3 Department of Dermatology, Poznan University of Medical Sciences, 49 Przybyszewskiego Street, \\ 60-356 Poznan, Poland; adamskiz@poczta.onet.pl \\ 4 Department of Computer Science and Statistics, Poznan University of Medical Sciences, \\ 79 Dabrowskiego Street, 60-529 Poznan, Poland; iza@ump.edu.pl \\ * Correspondence: justynagornowicz1@poczta.onet.pl; Tel.: +48-618691367
}

Received: 27 July 2020; Accepted: 3 September 2020; Published: 4 September 2020

\begin{abstract}
Phytoecdysteroids are natural compounds with therapeutic benefits in both humans and animals. The effectiveness of natural products with health potential is based on the activities and potencies of their active ingredients. In this study, dominant ecdysteroids-ajugasterone $C$, 20-hydroxyecdysone and polypodine B-from the Serratula coronata (S. coronata) herb were separated by column chromatography, identified by spectroscopic data and quantified by high-performance liquid chromatography with a diode array detector (HPLC-DAD). The obtained concentration of ecdysteroids (approximately $23 \%$ ) in the S. coronatae herb extract enhances the possibility of their use in pharmaceutical and cosmetic products with high levels of phytoecdysteroids. Moreover, this study has shown a positive effect of ecdysteroids-containing cream on changes in quality of life and a beneficial effect in reducing the symptoms of seborrheic dermatitis. It has been demonstrated that the application of the cream with phytoecdysteroids resulted in a statistically significant alleviation of symptoms $(p<0.05)$, especially in terms of itching, pain or burning sensations in the affected areas in comparison to previous symptoms.
\end{abstract}

Keywords: phytoecdysteroids; Serratula coronata; seborrheic dermatitis

\section{Introduction}

Phytoecdysteroids are a class of chemical compounds (triterpenoids) that are synthesized by plants for defense against insects. Over 300 plant ecdysteroid analogues have been identified so far with distinctive chemical, physical and biological properties. These compounds are derivatives of cyclopentane perhydrophenantrene. The vast majority of them have 27 atoms of carbon, with a double bond between $\mathrm{C} 7-\mathrm{C} 8$ and a keto group on C6. Ecdysteroids are characterized by methyl groups on $\mathrm{C} 10$ and $\mathrm{C} 13$ in the $\mathrm{B}$ configuration and by the double bond between $\mathrm{C} 7-\mathrm{C} 8$. Ecdysteroids isolated from the Centaureinae subtribe plants are further characterized by two $\mathrm{OH}$ groups on $\mathrm{C} 2$ 
and C3. Someecdysteroids-although only of vegetable origin-have an extra hydroxyl group on C1, C5, and C11 [1-4]. Plants usually contain a few major ecdysteroids, along with other closely related compounds that occur in lower amounts. The reliable qualitative and quantitative analysis of phytoecdysteroids isolated from plants are important for the development of new pharmaceutical products [2-6].

Pharmacological studies indicate numerous health benefits of phytoecdysteroids in both humans and animals. The compounds and materials in which they play a dominant role are very promising for phytotherapy [7-10]. Phytoecdysteroids have a positive effect on hypercholesterolemia, hyperglycemia, hypotension, infectious diseases and physical and mental weakness [8,11-18]. Puri et al. have found that 20-beta-hydroxyecdysone is efficient in the prevention of hot flushes in ovariectomized rats [19]. Several scientific reports have suggested the use of phytoecdysteroids as a supplement in the treatment of several diseases of the cardiovascular system [11-15,17]. A positive effect of phytoecdysteroids on human skin, including wound healing activity, has been postulated.

Seborrheic dermatitis (SD) is a common, chronic, recurrent inflammatory dermatosis that significantly decreases the quality of life of patients. Clinically, it is characterized by erythema and skin flaking, which occur most often in areas with a high concentration of sebaceous glands, including the face, scalp, ears, chest and body folds. This disease is a pervasive skin disorder that affects $3 \%$ of the population and may occur in patients from infancy to old age [20,21]. SD may appear as exfoliating yellow epidermis on a reddish background, sometimes accompanied by itching. Pruritus is often present in adult SD, especially when the scalp is involved. Due to pruritus and its chronic and recurring character, as well as the clinical manifestation in highly visible places, SD has a negative influence on patients' psychical condition and their self-esteem [22].

According to the current knowledge on SD treatment, there is a lack of a single radical therapy that is $100 \%$ effective and results in permanent clinical outcomes $[23,24]$. The therapy is centered on the topical application of antifungals and anti-inflammatory agents [24]. The primary treatment is based on imidazole preparations and corticosteroids, which have little effect. The overall treatment is used only in severe SD cases and includes imidazole derivatives [25]. Therefore, SD still remains difficult to treat and requires a personalized approach for each patient.

In light of the above, there is an increasing interest in phytoecdysones-natural steroids found in plants - which are seen as an alternative treatment and/or complementary skin care treatment for SD [26]. However, their immunological significance and possible therapeutic use in SD still remain unclear. Thus, in this study, we focused particularly on the use of main phytoecdysteroids isolated from the Serratula coronate herb for skin disorders such as SD.

The aim of this study was to develop and validate a simple, sensitive and precise method for the isolation and quantification of dominant ecdysteroids-ajugasterone C (1), polypodine B (2) and 20-hydroxyecdysone (3) - from the $S$. coronata herb (Table 1). The next step was to assess the clinical potential of a cream with a $2 \%$ concentration of ecdysteroids for reducing the symptoms of SD. 
Table 1. The chemical structures of dominant phytoecdysteroids from the S. coronata herb.

Source Active Molecule/Ecdysteroids

\section{Material and Methods}

\subsection{Plant Material}

Herbs of Serratula coronata L. (Compositae/Asteraceae) were collected during the dry seasons of 2013-2016 (in May each year) from the Botanical Garden at the Department of Medicinal and Cosmetic Natural Products, University of Medical Sciences in Poznan (Poland), where the voucher specimens (No. 64/2009) are deposited. S. coronata seedswere provided by the Botanical Garden in Vacratot (Hungary). They were gathered from a natural habitat in the north of Hungary. The aerial parts and seeds of S. coronata were identified by Karol Latowski of Adam Mickiewicz University in Poznan.

\subsection{Extractionand Identification of Ecdysteroids}

Dried herbs of S. coronata (330 g) were crushed and soaked in methanol (MeOH; Merck KGaA, Darmstadt, Germany) (1.32 L, three times). The MeOH extract was evaporated, and the residue was dissolved in distilled water $(0.5 \mathrm{~L})$. The aqueous extract was shaken with ethyl acetate (AcOEt; Merck KGaA, Darmstadt, Germany) (three times with 0.5 L). The AcOEt extract was evaporated, leaving $7.35 \mathrm{~g}$ of residue.

The compounds were separated by column chromatography on silica gel with a size of $0.063-200 \mathrm{~nm}$ (Merck Art. 7733, Darmstadt, Germany). Selected fractions were further rechromatographed on silica gel with a size of $<0.063 \mathrm{~nm}$ (Merck Art. 7729, Darmstadt, Germany).

The AcOEt extract was chromatographed on silica gel with mixtures of $n$-hexane and $\mathrm{Me}_{2} \mathrm{CO}$ (ratio 2:1) as eluent (Merck KGaA, Darmstadt, Germany). Two collected fractions needed purifying and were rechromatographed on silica gel with a mixture of dichloromethane $\left(\mathrm{CH}_{2} \mathrm{Cl}_{2} ; \mathrm{Merck} \mathrm{KGaA}\right.$, Darmstadt, Germany) and $\mathrm{MeOH}$ (ratio 5:1).

The ${ }^{1} \mathrm{H}(600 \mathrm{MHz})$ and ${ }^{13} \mathrm{C}$ NMR $(150 \mathrm{MHz})$ spectra were run on a Bruker Avance 600 instrument (Bruker, Billerica, Massachusetts, US) in deuterated chloroform $\left(\mathrm{CDCl}_{3}\right)$, deuterated methanol $\left(\mathrm{CD} \mathrm{D}_{3} \mathrm{OD}\right)$ 
or deuterated dimethyl sulfoxide (DMSO- $\left.d_{6}\right)$. Chemical shifts are given in ppm $(\delta)$ and coupling constants in $\mathrm{Hz}(J)$. Melting points were determined on a Büchi B-540 Melting Point apparatus (BÜCHI Labortechnik AG, Flawil, Switzerland) and are uncorrected.

Dried and crushed herbs of $S$. coronata $(620 \mathrm{~g})$ was soaked three times in ethanol (EtOH) (2.85 L) for $24 \mathrm{~h}$. The EtOH extract was evaporated and gave a residue-Extractum siccum (14 g)—which was used as the material for quantitative analysis and for the preparation of the standardized cream for application.

\subsection{Ecdysteroids Characterization}

For the characterization of compounds, ${ }^{1} \mathrm{H}$ NMR analysis was performed. Signals of vegetable ecdysteroids have been seen in the proton spectra of all three analysed compounds (Table S1): double bonds between C7-C8 (characteristic doublets from 5.80 for compounds 1 and 3 to 5.85 for compound 2).

The following signals are typical of compound 1 (Figure S1): a $4.10 \mathrm{ppm}$ signal on C11, which is from the proton on the hydroxyl group; and a $1.58 \mathrm{ppm}$ signal on C25, which means that there is no $\mathrm{OH}$ group in this location in the ecdysone's aliphatic chain, resulting in typical signals of two methyl groups on C26 (0.916 ppm) and on C27 (0.920 ppm). The 2.38 ppm signal, on the other hand, indicating the presence of a proton on $\mathrm{C} 5$ in compound $3^{\prime}$ s spectrum, distinguishes it from compound 2 (Figures S2 and S3).

\subsection{Quantification of Ecdysteroids Using HPLC-DAD Analysis}

Ajugasterone C (1) and polypodine B (2) were used for analysis after their purification and identification by spectral methods. The ecdysteroid 20-Hydroxyecdysone (3) $(1 \mathrm{mg} / \mathrm{mL}$ of methanol) in the form of a Certified Reference Material was purchased from Merck (KGaA, Germany). Solvents used for chromatographic analysis were of HPLC grade (Sigma Aldrich Sp. z o.o., Poznan, Poland).

The dry ethanol extract of the Serratula coronata herb was dissolved in methanol, in a final concentration of $20 \mathrm{~g} / \mathrm{L}$.

HPLC analyses were carried out using an Agilent 1200 SL system (Perlan Technologies, Germany). An analytical column with C8 silicone filling $-5 \mu \mathrm{m}$ (particle size), $125 \times 4 \mathrm{~mm}$ (length $\times$ ext. diameter; LiChrospher ${ }^{\circledR} 60$ RP-select B, $5 \mu \mathrm{m}$, LiChroCART ${ }^{\circledR}$ 125-4, Merck, Germany)—connected with a guard column with C8 silicone filling-5 $5 \mathrm{~m}, 4 \times 4 \mathrm{~mm}$ (LiChrospher ${ }^{\circledR} 60$ RP-select B, $5 \mu \mathrm{m}$, LiChroCART ${ }^{\circledR}$ 4-4, Merck, Germany) —was used to separate the compounds. HPLC analyses were carried out at ambient temperature (approximately $23{ }^{\circ} \mathrm{C}$ ), at a $1 \mathrm{~mL} / \mathrm{min}$ flow rate of the mobile phase, in UV absorption spectra, with a $\lambda_{\max }$ value of $242 \mathrm{~nm}$ in methanol, which is characteristic for ecdysteroids. Each sample injection of $15 \mu \mathrm{L}$ was performed in triplicate. The analyses were carried out using a gradient elution of water and methanol. The gradient elution scheme was as follows: $t_{0}(\mathrm{~min})$, $5 \% \mathrm{MeOH} ; \mathrm{t}_{12}, 30 \% \mathrm{MeOH} ; \mathrm{t}_{25}, 30 \% \mathrm{MeOH} ; \mathrm{t}_{30}, 5 \% \mathrm{MeOH}$; with a post time of 5 min.Data and chromatograms were collected using Chem Station for LC 3D system Rev. B.04.01 SP1 software from Agilent Technologies (Waldbronn, Germany).

Quantitative analysis was performed using a standard external method. Stock solutions of the analyzed compounds $(1.0 \mathrm{~g} / \mathrm{L}$ of methanol) were used to prepare the calibration curves. The peak area ratios of compounds 1-3 were determined for each calibration sample using a calibration curve from 300 to $1000 \mathrm{mg} / \mathrm{L}$. The linear equation describing the relationship between ajugasterone C (1), polypodine B (2) and 20-hydroxyecdysone (3) concentrations and peak area ratios was determined by least-squares weighted regression methods.The validation of the method was performed in accordance with the Food and Drug Administration (FDA) guidelines [27].Three standard curves were prepared on threedifferent days, and the appropriate regression statistics were determined. The limit of detection (LOD) andthe limit of quantitation (LOQ) were calculated by the determination of the signal-to-noise ratio $(\mathrm{S} / \mathrm{N})(\mathrm{LOD}=3 \times(\mathrm{S} / \mathrm{N})$; $\mathrm{LOQ}=10 \times(\mathrm{S} / \mathrm{N}))$. For the intra-day assay, six replicates at three different concentrations of quality control (QC) samples-low (300 mg/L), middle (500 mg/L) and high 
(1000 mg/L) — were analyzed. For the inter-day assay, six replicates of low, middle and high-quality control samples were analyzed daily on three consecutive days. The mean, standard deviation, relative standard deviation (RSD) and accuracy of the intra-day and inter-day experiments were calculated. The accuracy was calculated on the basis of the given formula (mean concentration found/concentration taken) $\times 100$. Accuracy and precision data for intra and inter-day assays for analyzed samples are given in Table 2.

Table 2. Intra-day and inter-day precision and accuracy of compounds 1-3 (quality control, QC; relative standard deviation, RSD).

\begin{tabular}{|c|c|c|c|}
\hline $\begin{array}{l}\text { Nominal Concentration } \\
\text { of QC Samples }(\mu \mathrm{g} / \mathrm{mL})\end{array}$ & $\begin{array}{l}\text { Predicted Concentration, } \\
\text { Mean } \pm S D(\mu \mathrm{g} / \mathrm{mL})\end{array}$ & RSD (\%) & Accuracy $(\%)$ \\
\hline \multicolumn{4}{|c|}{ A. Intra-day assays; $n=6$} \\
\hline \multicolumn{4}{|c|}{ Ajugasterone $\mathrm{C}$} \\
\hline QC low 300 & $291 \pm 1.95$ & 0.67 & 97 \\
\hline QC middle 500 & $483 \pm 3.39$ & 0.70 & 97 \\
\hline QC high 1000 & $967 \pm 12.23$ & 1.26 & 97 \\
\hline \multicolumn{4}{|c|}{ Polypodine B } \\
\hline QC low 300 & $318 \pm 1.91$ & 0.60 & 106 \\
\hline QC middle 500 & $491 \pm 3.69$ & 0.75 & 98 \\
\hline QC high 1000 & $997 \pm 9.50$ & 0.95 & 100 \\
\hline \multicolumn{4}{|c|}{ 20-hydroxyecdysone } \\
\hline QC low 300 & $288 \pm 1.61$ & 0.57 & 96 \\
\hline QC middle 500 & $510 \pm 3.40$ & 0.51 & 102 \\
\hline QC high 1000 & $991 \pm 7.58$ & 1.10 & 99 \\
\hline \multicolumn{4}{|c|}{ B. Inter-day assays; $n=6$} \\
\hline \multicolumn{4}{|c|}{ Ajugasterone $\mathrm{C}$} \\
\hline QC low 300 & $287 \pm 3.02$ & 1.05 & 96 \\
\hline QC middle 500 & $481 \pm 4.71$ & 0.98 & 96 \\
\hline QC high 1000 & $962 \pm 12.85$ & 1.34 & 96 \\
\hline \multicolumn{4}{|c|}{ Polypodine B } \\
\hline QC low 300 & $317 \pm 2.29$ & 0.72 & 106 \\
\hline QC middle 500 & $489 \pm 3.78$ & 0.77 & 98 \\
\hline QC high 1000 & $995 \pm 9.21$ & 0.93 & 100 \\
\hline \multicolumn{4}{|c|}{ 20-hydroxyecdysone } \\
\hline QC low 300 & $287 \pm 1.46$ & 0.51 & 96 \\
\hline QC middle 500 & $511 \pm 2.62$ & 0.51 & 102 \\
\hline QC high 1000 & $991 \pm 8.15$ & 0.82 & 99 \\
\hline
\end{tabular}

\subsection{Study Group and Antiseborrheic Activities}

The study protocol was approved by the Bioethics Committee, based on Polish legislation and Good Clinical Practice at the Poznan University of Medical Sciences, Poznan, Poland (ethical approval number 1082/08). Written informed consent was obtained from all participants.

After dermatological consultation, the study included 36 patients: 17 women and 19 men aged 18-65. All of them were in a good general state of health. The patients were diagnosed with erythema and skin exfoliation and complained of itching. The changes in their skin were diagnosed as mild-to-moderate SD and were present on average for seven years. There were 64 diagnosed changes in total, located mostly (in 97\%) on nasal alar creases, ears, central chest, anterior hairline.

The recipe for the cream was developed by the Department of Medicinal and Cosmetic Natural Products, Poznan University of Medical Sciences (Poznan, Poland). The active substance of the cream was previously described as a dry ethanol extract of the Serratula coronata herb containing three dominant ecdysteroids - ajugasterone C (1), polypodine B (2) and 20-hydroxyecdysone (3) —which constituted $2 \%$ of the cream. In this study, the examined ointments were prepared on the basis of a creamy Lekobaza ${ }^{\circledR}$ Pharma Cosmetic base (Fagron, Kraków, Poland) with amphiphilic properties. Lekobaza is a commercially available, multi-component medium with a $\mathrm{pH}$ close to the skin condition [28]. 
Before the application of cream, all patients were subjected to skin allergy tests using patches with hypoallergenic and water-resistant chambers (IQ Ultimate ${ }^{\mathrm{TM}}$ by Chemotechnique Diagnostics) filled with a $25 \mu \mathrm{L}$ aqueous extract from the Serratula coronata herb and $2 \mathrm{mg}$ of the cream.

Each patient used $8 \mathrm{mg}$ of the cream, which was applied directly to the changed skintwo times a week for six weeks. The effectiveness of the cream was evaluated by a dermatologist during each control visit-that is, after two, four, and six weeks of application-and documented in a Termoquolity index questionnaire. Patients in the study group did not use any other preparations for the skin changes and were asked not to ingest any oral medicines or food which could have affected the changed skin.

The effect of using the tested cream on changes in quality of life was determined using a Termoquality index survey (four-item itch questionnaire) [29]. An assessment of four pruritus features was made, which is the most troublesome symptom of SD. Patients (19 men and 17 women) scored on a scale of 1 to 5 the extent (location, duration), severity and frequency of pruritus and its effect on sleep difficulties.

\subsection{Data Processing and Statistical Analysis}

Test results were analyzed statistically using Statistica 12 software (StatSoftPoland, Cracow, Poland) by StatSoft. Statistical significance was $\alpha=0.05$. A result was deemed statistically significant if $p<\alpha$. The Wilcoxon signed-rank test was used to compare the results before and after the application of cream.

\section{Results and Discussion}

\subsection{Isolation of Dominant Phytoecdysones from the S. coronata Herb}

As a result of our experiment, two fractions were isolated, one of which contained a chromatographically homogenous compound: ajugasterone C (1) $\left(65.3 \mathrm{mg}\right.$, m.p. $\left.210-214{ }^{\circ} \mathrm{C}\right)$.

The second collected fraction $(890 \mathrm{mg}$ ) contained a mixture of two compounds (but without the previously isolated one), which required purifying and was rechromatographed on silica gel with a different mixture: dimethyl chloride $\left(\mathrm{CH}_{2} \mathrm{Cl}_{2}\right)$ : methanol $(\mathrm{MeOH})($ ratio 10:1 then 7:1 and 5:1). As a result two compounds were isolated: polypodine B (2) $\left(93 \mathrm{mg}, \mathrm{m} . \mathrm{p} .225-227^{\circ} \mathrm{C}\right)$ and 20-hydroxyecdysone (3) $\left(220 \mathrm{mg}, 243-244^{\circ} \mathrm{C}\right)$.

\subsection{Thin Layer Chromatography (TLC) of the Isolated Compounds}

After the visualization of the chromatograms of the AcOEt extract from the S. coronata herb, three principal spots appeared: one of them was purple and two were dark blue. Figure 1 shows a clear separation of the purple spot of compound 1, and Figure 2 shows a clear separation between the two dark blue spots of compounds 2 and 3 . Interestingly, the TLC study showed the characteristic behaviour of polypodine B (2) on the chromatograms. This is a more polar compound than 20-hydroxyecdysone (3) (due to the additional hydroxyl group at C5) and should theoretically be placed below compound 3 on the chromatogram. However, this reasoning is valid only for a solvent system without methanol (Figure 1). When we used a developing phase containing methanol (Figure 2), compound 2 exhibited a higher running spot compared to compound 3. A possible explanation of the change in the polarity of polypodine B (2) is the presence of both the hydroxyl group at position 5 and carbonyl oxygen at C6 [30]. 
Figure 1. Thin-layer chromatography (TLC) of the purified AcOEt extract and phytoecdysteroids isolated from the $S$. coronata herb 1 . ajugasterone $C ; 2$. 20-hydroxyecdysone; 3 . polypodine $\mathrm{B} ; 4$. AcOEt extract of the S. coronata herb; adsorbent: silica gel; mobile phase: n-hexane:Me2CO 2:1.

Figure 2. TLC of the purified ACOEt extract and phytoecdysteroids isolated from the $S$. coronata herb 1. 20-hydroxyecdysone; 2 . polypodine B; 3 . AcOEt extract of the S. coronata herb; 4 . ajugasterone C; adsorbent: silica gel; mobile phase: $\mathrm{CH} 2 \mathrm{Cl} 2-\mathrm{MeOH}$ 5:1.

\subsection{HPLC Analysis}

In this study, dominant ecdysteroids from Serratula coronate were successfully separated using the HPLC-DAD method. Calibration curves for all compounds were linear in the range of 300-1000 $\mu \mathrm{g} / \mathrm{mL}$ (1: $y=12710 x+44.872, R^{2}=0.9997 ; 2: y=16907 x+54.195, R^{2}=0.9996 ; 3: y=11443 x-50.195$, $\left.\mathrm{R}^{2}=0.9995\right)$.

The limits of detection (LOD) for compounds 1-3 were 18, 4.5 and $15 \mu \mathrm{g} / \mathrm{mL}$, respectively. The limits of quantification (LOQ) for ajugasterone C (1), polypodine B (2), 20-hydroxyecdysone (3) were 60,15 and $50 \mu \mathrm{g} / \mathrm{mL}$, respectively.

The analysis of independent low, middle and high-quality control samples was used to perform the intra-day and inter-day assay. The intra-day RSD for compounds 1-3 ranged from $0.67 \%$ to $1.26 \%$ for ajugasterone C (1), from $0.60 \%$ to $0.95 \%$ for polypodine B (2) and from $0.51 \%$ to $1.10 \%$ for 
20-hydroxyecdysone (3); additionally, an accuracy of $97 \%$ was achieved for compound 1, between $98 \%$ and $106 \%$ for compound 2 and $96 \%$ and 102\% for compound 3 (Table 2).

The inter-day relative standard deviation (RSD) for compounds 1-3 varied from $0.98 \%$ to $1.34 \%$ for 1 , from $0.72 \%$ to $0.93 \%$ for 2 and from $0.51 \%$ to $0.82 \%$ for 3; furthermore, an accuracy of $96 \%$ was achieved for for ajugasterone C (1), between $98 \%$ and $106 \%$ for polypodine B (2) and $96 \%$ and $102 \%$ for 20-hydroxyecdysone (3) (Table 2). The above results indicated that the method was reliable, reproducible and accurate.

The validated method was applied to the determination of compounds 1-3 in plant material extract (Figure 3) after column chromatography separation.

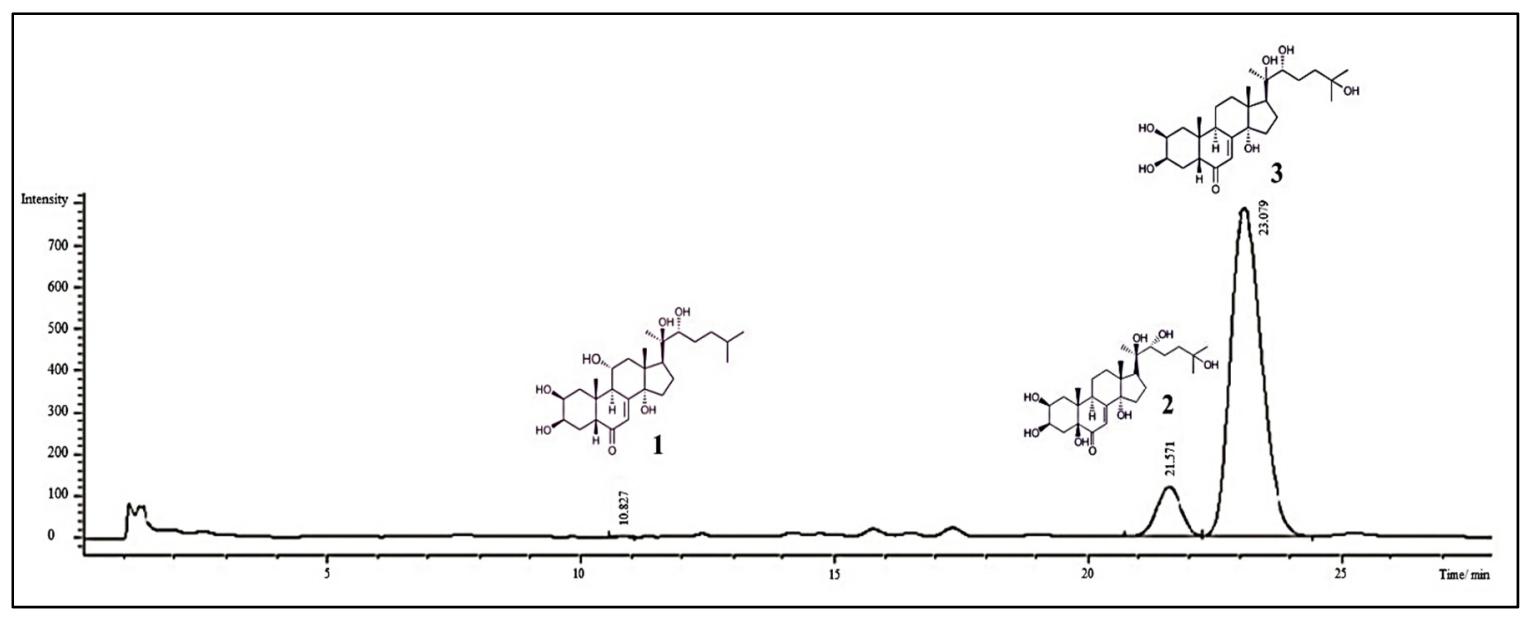

Figure 3. Chromatogram of $S$. coronata extract $(10 \mathrm{mg} / \mathrm{mL})$ : ajugasterone $C$ (1):less than limit of quantification (LOQ); polypodine B (2): $0.358 \mathrm{mg} / \mathrm{mL}$ (35.8 mg/g of extract); 20-hydroxyecdysone (3): $1.901 \mathrm{mg} / \mathrm{mL}$ (190.1 mg/g of extract); total compounds: $2.289 \mathrm{mg} / \mathrm{mL}(228.9 \mathrm{mg} / \mathrm{g}$ of extract $) \cong 22.59 \%$.

The obtained $22.89 \%$ concentration of phytoecdysteroids in the S. coronata herb extract of these compounds guarantees the possible use of the standardized extract as an effective ingredient in cosmetics and drug production with this unique group of natural compounds.

It should be noticed that isomers in rare cases are not identifiable by mass spectrometry (MS) because they produce identical spectra. In our work, the ${ }^{1} \mathrm{H}$ NMR analysis indicated the details of the structures of the three compounds from the plant extract. Two of the compounds (ajugasterone $\mathrm{C}$ and 20-hydroxyecdysone) are isomers; therefore, by MS, the substitution sites ofOH groups are indistinguishable. The consequence of this approach is the misinterpretation of ajugasterone $\mathrm{C}$ and 20-hydroxyecdysone as synonyms. Therefore, we decided to use NMR in our study as the best method for structural analysis.

\subsection{Examination of $2 \%$ Phytoecdysteroids Cream for Seborrheic Dermatitis}

During the six weeks of the application of the cream, the quality of the patients' life improved significantly, and in $97 \%$ of cases, following the use of the cream with phytoecdysteroids, the epidermis reverted to its physiological state as assessed by a dermatologist. Moreover, there was no report of any side effects of the cream. It has been shown that applying the cream with phytoecdysteroids resulted in a statistically significant alleviation of symptoms $(p<0.05)$, especially in terms of itching, pain or burning sensations in the affected areas in comparison to previous symptoms. The results obtained before and after the application of the cream are presented in Figure 4. 


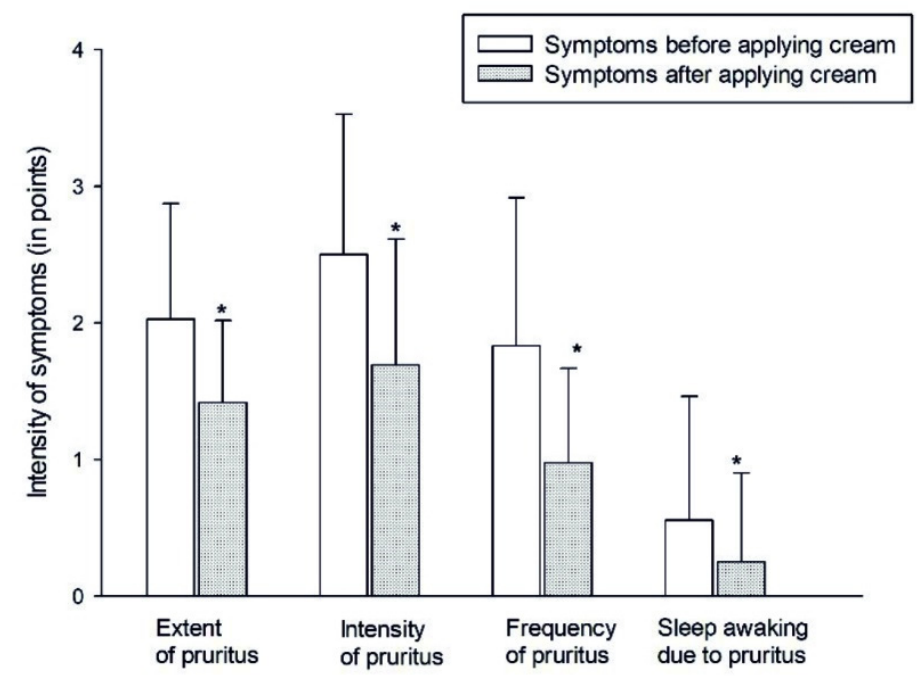

Figure 4. Comparison of termoquality index survey results before and after the usage of cream with $2 \%$ of ecdysteroids extract from the $S$. coronata herb. * - statistically significant difference compared to the result observed previously ( $p<0.05$; the Wilcoxon signed-rank test).

There are scientific reports which have suggested that phytoecdysteroids have anti-inflammatory and antioxidant properties as well as a positive effect on metabolic diseases, infectious diseases and physical and mental weakness $[3,8,11,12,14-18,31]$. Rosselli et al. have shown that ecdysones have cytotoxicity potential against rat C6 glioma cells [32]. However, further studies of the application of phytoecdysteroids in medicine are still needed.

The method used in this study could be adapted for the future evaluation of ajugasterone $C(\mathbf{1})$, 20-hydroxyecdysone (2) and polypodine B (3) concentrations in patients' plasma during the application of the cream. The obtained concentration of ecdysteroids (approximately 23\%)in the Serratula coronata herb extract enhances their potential use in cosmetics and drug production with this unique group of natural compounds.

The results obtained in this study, after six weeks of usage of phytoecdysteroid-containing cream, were satisfactory. The quality of patients' life improved considerably due to significant alleviation of symptoms $(p<0.05)$, especially in terms of itching, pain or burning sensations in the SD-affected areas. In $97 \%$ of the cases, following the use of the cream with phytoecdysteroids, the epidermis reverted to its physiological state. Moreover, there was no report of any side effects of the cream.

The precise molecular mechanisms describing the pharmacological activity of phytoecdysteroids in an unusual skin condition still remain unexplored. However, it is known that the action of phytoecdysteroids is associated with skin barrier function recovery. Data in the literature indicated that phytoecdysones might promote keratinocyte differentiation in vitro [33]. Thus, the positive effect of the application of phytoecdysteroid-containing cream in SD patients may be associated with the normalization of the keratinocytes differentiation process. It is postulated [34,35] that ecdysones may have a significant impact on the reduction of inflammation, probably due to their immunomodulatory function and the modulation of the level of the pro-inflammatory cytokine (e.g.,interleukin-6 (IL-6), tumor necrosis factor alpha (TNF- $\alpha)$ ). Moreover, it has been reported that phytoecdysteroids improve skin quality by accelerating the healing of wounds and burns [36,37].Several studies [38] have claimed associations between Malassezia restricta lipase and SD. In light of this, ecdysteroids, especially 20-hydroxyecdysone, probably enhance antifungal immunity, resulting in a reduction of disease symptoms [39].

Therefore, it can be expected that the use of phytoecdysteroids might have a long-term impact on skin changes in patients with SD, and potential recurrences of the condition might be delayed. Cream with natural steroids may also be helpful for other skin disorders resulting in itching, as well as atopic 
dermatitis. No side effects were observed, which frequently occur during the application of a cream with synthetic steroids [23].

The results of our study give dermatologists, cosmetologists and patients hope for an efficient and safe skin care method. The positive results of applying the cream with a $2 \%$ content of ecdysteroids in seborrheic dermatitis are promising for the development of a new drug for skin diseases which cause pruritus.

\section{Conclusions}

The use of the $S$. coronata herb, with a high concentration of ecdysteroids-ajugasterone C (1), polypodine $\mathrm{B}(2)$ and 20-hydroxyecdysone (3) - and with bioactive properties, appears to be a promising strategy for the preparation of valuable pharmaceutical and cosmetic products. The positive results of applying the cream with a $2 \%$ standardized extract content of ecdysteroids in seborrheic dermatitis suggest its potential new application for skin diseases which cause pruritus. The simple but effective method for isolating active phytoecdysones presented in this paper maybe useful infuture study.

Supplementary Materials: The following are available online at http://www.mdpi.com/1660-4601/17/18/6453/s1, Figure S1: ${ }^{1} \mathrm{H}$ NMR $\left(600 \mathrm{MHz}, \mathrm{CD}_{3} \mathrm{OD}\right)$ spectrum of compound 1, Figure S2: ${ }^{1} \mathrm{H}$ NMR $\left(600 \mathrm{MHz}, \mathrm{CD}_{3} \mathrm{OD}\right)$ spectrum of compound 2, Figure S3: ${ }^{1} \mathrm{H}$ NMR $\left(600 \mathrm{MHz}, \mathrm{CD}_{3} \mathrm{OD}\right)$ spectrum of compound 3, Table S1: ${ }^{1} \mathrm{H}$ NMR data (600.20 MHz) of ajugasterone $\mathrm{C}(\mathbf{1})$, polypodine $\mathrm{B}(\mathbf{2})$ and 20-hydroxyecdysone (3) (in $\mathrm{CD}_{3} \mathrm{OD}$ ).

Author Contributions: Conceptualization, G.N. and J.N.; Methodology, M.N., J.G.-P. and A.M.; Software, M.N.; I.M.; Validation, M.N.; Formal analysis, M.N. and I.M.; Investigation, M.N., A.K. and Z.A.; Resources, G.N. and E.F.; Writing—original draft preparation, M.N.; Writing—Review and Editing, M.N., J.G.-P., G.N., J.N and E.F.; Supervision, G.N. and E.F. All authors have read and agreed to the published version of the manuscript.

Funding: This research did not receive any specific grant from funding agencies in the public, commercial, or not-for-profit sectors.

Acknowledgments: The authors thank Maria Urbańska for her assistance and technical support.

Conflicts of Interest: The authors declare no conflict of interest.

\section{References}

1. Dinan, L. Phytoecdysteroids: Biological aspects. Phytochem 2001, 57, 325-339. [CrossRef]

2. Santagati, N.; Tropea, S.; Ronsisvalle, G. Analysis of ecdysteroids by micellar electrokinetic chromatography with on-line preconcentration. J. Chromatogr. A 2005, 1081, 77-86. [CrossRef] [PubMed]

3. Lapenna, S.; Dinan, L. HPLC and TLC characterization of ecdysteroid alkyl ethers. J. Chromatogr. B 2009, 877, 2996-3002. [CrossRef] [PubMed]

4. Takács, M.; Simon, A.; Liktor-Busa, E.; Báthori, M.; Zsila, F.; Bikádi, Z.; Horváth, P.; Veress, G.; Gergely, A.; Tóth, G. Structure and stereochemistry of novel ecdysteroids from the roots of Serratulawolffii. Magn. Reson. Chem. 2010, 48, 386-391. [CrossRef] [PubMed]

5. Simon, L.A.; Ványolós, A.; Béni, Z.; Dékány, M.; Tóth, G.; Báthori, M. Ecdysteroids from Polypodium vulgare L. Steroids 2011, 76, 1419-1424. [CrossRef]

6. Thiem, B.; Kikowska, M.; Maliński, M.P.; Kruszka, D.; Napierała, M.; Florek, E. Ecdysteroids: Production in plant in vitro cultures. Phytochem. Rev. 2017, 16, 603-622. [CrossRef]

7. Báthori, M.; Pongrácz, Z. Phytoecdysteroids-from isolation to their effects on humans. Curr. Med. Chem. 2005, 12, 153-172. [CrossRef]

8. Chen, Q.; Xia, Y.; Qiu, Z. Effect of ecdysterone on glucose metabolism in vitro. Life Sci. 2006, 78, 1108-1113. [CrossRef]

9. Festucci-Buselli, R.A.; Contim, L.A.; Barbosa, L.C.; Stuart, J.; Otoni, W.C. Biosynthesis and potential functions of the ecdysteroid 20-hydroxyecdysone-a review. Botany 2008, 86, 978-987. [CrossRef]

10. Dinan, L. The Karlson Lecture. Phytoecdysteroids: What use are they? Arch. Insect Biochem. Physiol. 2009, 72, 126-141. [CrossRef]

11. Lafont, R.; Dinan, L. Practical uses for ecdysteroids in mammals including humans: An update. J. Insect Sci. 2003, 3, 1-30. [CrossRef] 
12. Wilborn, C.D.; Taylor, L.W.; Campbell, B.I.; Kerksick, C.; Rasmussen, C.J.; Greenwood, M.; Kreider, R.B. Effects of methoxy isoflavone ecdysterone and sulfo-polysaccharide supplementation on training adaptations in resistance-trained males. J. Inter. Soc. Sports Nutr. 2006, 3, 19-27. [CrossRef] [PubMed]

13. Báthori, M.; Tóth, N.; Hunyadi, A.; Márki, A.; Zádor, E. Phytoecdysteroids and anabolic-androgenic steroids—structure and effects on humans. Curr.Med. Chem. 2008, 15, 75-91. [CrossRef] [PubMed]

14. Punegov, V.V.; Sychov, R.L.; Zainullin, V.G.; Fedorov, V.N.; Pangeova, N.V. Extraction of ecdysteron-80 from Serratulacoronata L. and assessment of its pharmacological action. Part I. Adaptogenic, gastroprotective, thermo protective, and antihypoxic activity. Pharm. Chem.J. 2008, 42, 446-451. [CrossRef]

15. Kumpun, S.; Girault, J.P.; Dinan, L. The metabolism of 20-hydroxyecdysone in mice: Relevance to pharmacological effects and gene switch applications of ecdysteroids. J. Steroid Biochem. Mol. Biol. 2011, 126, 1-9. [CrossRef]

16. Mamadalieva, N.Z.; El-Readi, M.Z.; Janibekov, A.A.; Tahrani, A.; Wink, M. Phytoecdysteroids of Silene guntensis and their in vitro cytotoxic and antioxidant activity. Z. Naturforsch. C 2011, 66, 215-224. [CrossRef]

17. Syrov, V.N.; Iudasheva, N.K.; Egarnova, F.R.; Ismailova, G.I.; Abdulaeev, N.D.; Khusbaktova, Z.A. Estimation of the hypoglycemic effect of phytoecdysteroids. Eksp Klin Farm. 2012, 75, $28-31$.

18. Ochieng, C.O.; Ishola, I.O.; Opiyo, S.A.; Manguro, L.A.; Owuor, P.O.; Wong, K.C. Phytoecdysteroids from the stem bark of Vitex doniana and their anti-inflammatory effects. Planta Med. 2013, 791, 52-59. [CrossRef]

19. Puri, P.; Wuttke, W.; Seidlova-Wuttke, D. 20-OH-ecdysone prevents hot flushes in ovariectomized rats. Planta Med. 2012, 78, 109-114. [CrossRef]

20. Dessinioti, C.; Katsambas, A. Seborrheic dermatitis: Etiology, risk factors, and treatments: Facts and controversies. Clin.Dermatol. 2013, 31, 343-351. [CrossRef]

21. Borda, L.J.; Perper, M.; Keri, J.E. Treatment of seborrheic dermatitis: A comprehensive review. J. Dermatolog. Treat. 2019, 30, 158-169. [CrossRef]

22. Clark, G.W.; Pope, S.M.; Jaboori, K.A. Diagnosis and treatment of seborrheic dermatitis. Am. Fam. Phys. 2015, 91, 185-190.

23. Elgash, M.; Dlova, N.; Ogunleye, T.; Taylor, S.C. Seborrheic Dermatitis in Skin of Color: Clinical Considerations. J. Drugs Dermatol. 2019, 18, 24-27. [PubMed]

24. Wikramanayake, T.C.; Borda, L.J.; Miteva, M.; Paus, R. Seborrheic dermatitis—Looking beyond Malassezia. Exp. Dermatol. 2019, 28, 991-1001. [CrossRef] [PubMed]

25. Hajar, T.; Leshem, Y.A.; Hanifin, J.M.; Nedorost, S.T.; Lio, P.A.; Paller, A.S.; Block, J.; Simpson, E.L. A systematic review of topical corticosteroid withdrawal ("steroid addiction") in patients with atopic dermatitis and other dermatoses. J.Am. Acad. Dermatol. 2015, 72, 541-549.e2. [CrossRef] [PubMed]

26. Ramazanov, N.S.; Bobayev, I.D.; Yusupova, U.Y.; Aliyeva, N.K.; Egamova, F.R.; Yuldasheva, N.K.; Syrov, V.N. Phytoecdysteroids-containing extract from Stachys hissarica plant and its wound-healing activity. Nat. Prod. Res. 2017, 31, 593-597. [CrossRef]

27. U.S. Food and Drug Administration (FDA). Q2B Validation of Analytical Procedures: Methodology, Guidance for Industry. 1996. Available online: http://www.fda.gov/cder/Guidance/1320fnl.pdf (accessed on 1 September 2020).

28. Siemiradzka, W.; Dolińska, B.; Ryszka, F. Influence of concentration on release and permeation process of model peptide substance-corticotropin-from semisolid formulations. Molecules 2020, 25, 2767. [CrossRef]

29. Reich, A.; Mędrek, K.; Szepietowski, J. Four-item itch questionnaire-validation of questionnaire. Dermatol. Rev. (Przeglad Dermatol.) 2012, 99, 600-604.

30. Nowak, G.; Urbańska, M.; Nawrot, J.; Bernard, M.K.; Dawid-Pać, R. Color and chemical reactions of selected sesquiterpene lactones and ecdysones from Asteraceae on TLC plates. J. Planar Chromatogr. 2013, 26, $289-293$. [CrossRef]

31. Gorelick-Feldman, J.; MacLean, D.; Ilic, N.; Poulev, A.; Lila, M.A.; Cheng, D.; Raskin, I. Phytoecdysteroids increase protein synthesis in skeletal muscle cells. J. Agric. Food Chem. 2008, 56, 3532-3537. [CrossRef]

32. Rosselli, S.; Maggio, A.; Bruno, M.; Spadaro, V.; Formisano, C.; Irace, C.; Maffettone, C.; Mascolo, N. Furostanol saponins and ecdysones with cytotoxic activity from Helleborus bocconei ssp. Intermedius. Phytother. Res. 2009, 23, 1243-1249. [CrossRef] [PubMed]

33. Detmar, M.; Dumas, M.; Bonté, F.; Meybeck, A.; Orfanos, C.E. Effects of ecdysterone on the differentiation of normal human keratinocytes in vitro. Eur. J. Derm. 1994, 4, 558-562. 
34. Naggar, Y.A.; Ghorab, M.; Mohamed, K. Phytoecdysteroids: Isolation and biological applications. A J. Life Sci. 2017, 5, 7-10. [CrossRef]

35. Patel, S.S.; Savjani, J.K. Systematic review of plant steroids as potential anti-inflammatory agents: Current status and future perspectives. J. Phytopharm. 2015, 4, 121-125.

36. Meybeck, A.; Bonté, F. Ecdysteroid-containing liposomes for wound healing and skin regeneration. Chem. Abstr. 1990, 133, 30138r.

37. Dinan, L.; Lafont, R. Effects and applications of arthropod steroid hormones (ecdysteroids) in mammals. J. Endocrinol. 2006, 191, 1-8. [CrossRef]

38. Ali, S.; Khan, F.I.; Mohammad, T.; Lan, D.; Hassan, M.I.; Wang, Y. Identification and evaluation of inhibitors of lipase from Malassezia restricta using virtual high-throughput screening and molecular dynamics studies. Int. J. Mol. Sci. 2019, 20, 884. [CrossRef]

39. Han, P.; Han, J.; Zhang, M.; Fan, J.; Gong, Q.; Ma, E.; Zhang, J. 20-Hydroxyecdysone enhances Immulectin-1 mediated immune response against entomogenous fungus in Locusta migratoria. Pest Manag. Sci. 2020, 76, 304-313. [CrossRef]

(C) 2020 by the authors. Licensee MDPI, Basel, Switzerland. This article is an open access article distributed under the terms and conditions of the Creative Commons Attribution (CC BY) license (http://creativecommons.org/licenses/by/4.0/). 